\title{
Spatiotemporal Dynamics of Total Viable Vibrio spp. in a NW Mediterranean Coastal Area
}

\author{
LÉa Girard ${ }^{1 \dagger}$, Sébastien Peuchet ${ }^{1 \dagger}$, Pierre Servais ${ }^{2}$, AnNabelle Henry ${ }^{3}$, Nadine Charni-Ben-Tabassi ${ }^{3}$, \\ and JULIA BAUDART ${ }^{*}$
}

${ }^{1}$ Sorbonne Universités, UPMC Univ. Paris 06, CNRS, Laboratoire de Biodiversité et Biotechnologies Microbiennes (LBBM),
Observatoire Océanologique de Banyuls sur mer, F-66650 Banyuls sur Mer, France; ${ }^{2}$ Ecologie des Systèmes Aquatiques,
Université Libre de Bruxelles, Bruxelles, Belgium; and ${ }^{3}$ Veolia Environnement, Centre d'Analyses Environnementales, Saint
Maurice, France

(Received February 17, 2017—Accepted May 21, 2017—Published online July 19, 2017)

A cellular approach combining Direct Viable Counting and Fluorescent In Situ Hybridization using a one-step multiple-probe technique and Solid Phase Cytometry (DVC-FISH-SPC) was developed to monitor total viable vibrios and cover the detection of a large diversity of vibrios. FISH combined three probes in the same assay and targeted sequences located at different positions on the 16S rRNA of Vibrio and Aliivibrio members. We performed a 10-month in situ study to investigate the weekly dynamics of viable vibrios relative to culturable counts at two northwestern Mediterranean coastal sites, and identified the key physicochemical factors for their occurrence in water using a multivariate analysis. Total viable and culturable cell counts showed the same temporal pattern during the warmer season, whereas the ratios between both methods were inverted during the colder seasons $\left(<15^{\circ} \mathrm{C}\right)$, indicating that some of the vibrio community had entered into a viable but non-culturable (VBNC) state. We confirmed that Seawater Surface Temperature explained $51-62 \%$ of the total variance in culturable counts, and also showed that the occurrence of viable vibrios is controlled by two variables, pheopigment (15\%) and phosphate (12\%) concentrations, suggesting that other unidentified factors play a role in maintaining viability.

Key words: vibrio, viability, FISH, solid phase cytometry, coastal area

The genus Vibrio is widely distributed in coastal waters, and many species are known to be involved in human and animal waterborne and foodborne diseases worldwide. Therefore, it is important for monitoring programs to understand the causality of Vibrio-related diseases. The implementation of monitoring programs requires rapid methods to detect vibrios including pathogenic Vibrio strains in coastal waters. Thiosulfate Citrate Bile salt Sucrose (TCBS) medium has been extensively used to recover a large range of Vibrio species from environmental samples $(21,38,43,46)$. Nevertheless, it shows some limitations for the quantification of Vibrio species in natural bacterial communities. Previous studies estimated that the specificity of TCBS medium for the genus Vibrio was approximately $60 \%(20,34)$. Growth inhibitors of intestinal bacteria are present in TCBS medium, such as sodium citrate, sodium sulfate, and bile salts, which prevent the growth of some Vibrio species and injured cells $(9,42,55)$.

Several species pathogenic for human and marine vertebrates and invertebrates are known to enter into a viable but non-culturable state (VBNC) under unfavorable environmental conditions. This physiological condition is a reversible state that ends with the resuscitation of pathogens when conditions once again become favorable. In this dormant state, cells remain viable, but not detectable by conventional culture-based methods and may show higher resistance to exogenous stresses and the maintenance of active virulence factors $(15,28,37)$. Cellular or molecular approaches, such as FISH and qPCR,

\footnotetext{
* Corresponding author. E-mail: baudart@obs-banyuls.fr;

Tel: (33) 4688873 47; Fax: (33) 468887398.

$\dagger$ These authors contributed equally to this work.
}

offer more specific and sensitive detection by targeting a specific rRNA sequence, but are not informative on the physiological state of cells when used alone $(11,19,35,47,53)$. Therefore, with the perspective of monitoring programs, rapid methods must be informative of cell viability.

The entrance of different Vibrio species into the VBNC state may be induced by several distinct environmental factors. Low nutrient concentrations, suboptimal or reduced temperatures, elevated salinities, extreme $\mathrm{pH}$, and solar radiation are important for inducing the VBNC state in Vibrio (15-17). Since coastal zones are the interface between land and sea, they are the receptacle of continental inputs inducing high temporal fluctuations. This environmental imbalance may result in rapid changes in the physiology of heterotrophic bacteria such as Vibrio spp..

Previous studies reported rapid methods that combine the evaluation of cell viability and specific detection of pathogen species. Most of these studies focused on common pathogens such as $V$. cholera and $V$. parahaemolyticus (39-41), while few described a combined approach for $V$. alginolyticus and $V$. harveyi $(16,44)$. However, it is fundamental to quantify all Vibrio spp. in order to understand the factors leading to an increase in pathogenic species within the Vibrio community. A single species count gives limited information if results are not compared with the total abundance of viable Vibrio. Moreover, other Vibrio species may have pathogenic potential for humans such as $V$. mimicus, $V$. fluvialis, $V$. furnissii, $V$. damsela, $V$. metschnikovii, V. cincinnatiensis, and V. carchariae (56).

The aim of the present study is to develop a DVC-FISHSPC method that detects total viable Vibrio in seawater and monitors their dynamics in coastal areas. This approach was 
applied to a 10-month in situ study in order to compare with TCBS counts and was performed at two northwestern Mediterranean coastal sites (Pyrénées Orientales, France).

\section{Materials and Methods}

In silico probe specificity

Three oligonucleotide probes targeting specific sequences located at different positions on 16S rRNA (GV, Vib572a and Vib749) (18, $22,24)$ were selected from the literature based on their specificity and closest melting temperature $(\mathrm{Tm})$ (Table 1$)$. The specificity of each probe was tested in silico with the ProbeCheck webserver (http://131.130.66.200/cgi-bin/probecheck/content.pl?id=home/) (30). Since we used multiple probes in the same hybridization solution, the presence of secondary structures within a probe (self dimers) and between probes (cross dimers) was examined using the PCR Primer Stats module of the Sequence Manipulation Suite (http:// www.ualberta.ca/ stothard/javascript/index.html), and the software Oligo (http://www.oligo.net/). Oligonucleotides were synthesized and conjugated at their $5^{\prime}$ end with 6-FAM (Thermo Fisher Scientific, Ulm, Germany).

\section{Direct Viable Count (DVC)}

The viability of cells was tested by a modified DVC assay initially developed by Kogure et al. (26). Water samples (volumes ranged between 0.1 and $50 \mathrm{~mL}$ ) were filtered on a $0.45-\mu \mathrm{m}$ black polyester membrane (CB04, Cycloblack, 25 mm, Biomérieux, France), placed on a $90-\mathrm{mm}$ cellulose pad (Whatman) soaked in $2 \mathrm{~mL}$ of non-selective marine nutritive broth (Difco) containing nalidixic acid, (Sigma Aldrich, Saint Quentin Fallavier, France), and then incubated at $30^{\circ} \mathrm{C}$ for $2 \mathrm{~h}$. The final concentration of nalidixic acid used in this assay was $20 \mu \mathrm{g} \mathrm{mL}^{-1}(1,9,16,44)$. The FISH procedure was then performed directly on the membrane as detailed below. DVC-positive cells showed a high fluorescent signal due to the high ribosomal content.

\section{Fluorescent in situ Hybridization (FISH).}

Hybridization conditions were optimized as follows. After the DVC treatment, the CB04 membrane was transferred onto a $25-\mathrm{mm}$ cellulose pad (Whatman) soaked in $600 \mu \mathrm{L}$ of $96.2 \%$ ethanol. The membranes were dried at room temperature for $3 \pm 1 \mathrm{~min}$. Hybridization was performed in $50 \mu \mathrm{L}$ of buffer $\left(900 \mathrm{mmol} \mathrm{L}^{-1} \mathrm{NaCl}, 10 \mathrm{mmol} \mathrm{L}^{-1}\right.$ Tris- $\mathrm{HCl}[\mathrm{pH} 7.2], 0.1 \%$ sodium dodecyl sulfate, $30 \%$ deionized formamide, and $10 \%$ dextran sulfate) containing the three probes (the final concentration of each probe was $2.5 \mathrm{ng} \mu \mathrm{L}^{-1}$ ) in hybridization chambers and incubated at $46^{\circ} \mathrm{C}$ for $120 \mathrm{~min}$ in a covered water bath. The auto-fluorescence of the environmental samples was reduced by supplying hybridization buffer with $0.1 \mathrm{mg} \mathrm{mL}^{-1}$ of PolyA, $0.05 \%$ of bovine serum albumin, and $0.01 \%$ of Evans blue dye.

Following hybridization, the membrane was placed on a $25-\mathrm{mm}$ diameter cellulose pad soaked in $600 \mu \mathrm{L}$ of washing buffer (40 mmol L ${ }^{-1} \mathrm{NaCl}, 10 \mathrm{mmol} \mathrm{L}-1$ Tris- $\mathrm{HCl}$ [pH 7.2], 0.01\% sodium dodecyl sulfate, and $5 \mathrm{mmol} \mathrm{L}^{-1}$ EDTA) and the membrane was kept at room temperature before being analyzed.

\section{DVC-FISH control samples}

Two controls were performed for each water sample to evaluate the efficiency of the DVC test and auto-fluorescent background of environmental samples. We initially performed the FISH procedure without the DVC treatment and any hybridized cells were counted by Solid phase cytometry (SPC), which indicated that untreated
DVC cells presented an undetectable fluorescence. This result emphasized the importance of the DVC treatment to improve cell enumeration. A no-probe control was then conducted and revealed the absence of false positive counts.

\section{SPC detection and enumeration}

Hybridized cells were enumerated using the solid phase cytometer, SPC (ScanRDI ${ }^{\mathrm{TM}}$, Biomérieux). Following the washing step, the membrane was placed into the sample holder and on a $25-\mathrm{mm}$ diameter cellulose membrane (support pad, pore size of $0.45 \mu \mathrm{m}$, Biomérieux), which had been saturated with $100 \mu \mathrm{L}$ of washing buffer. The SPC system scanned the membrane on the support pad with an argon laser beam (488 $\mathrm{nm}$ emission wavelength), recording all fluorescence events at 500-530 nm and 540-570 nm with two photomultiplier tubes. Fluorescence events were discriminated as a targeted fluorescent bacterial signal or false positive (auto-fluorescent particles) using a set of discriminant parameters (32). In our case, discriminant parameters were as follows: peak intensity 50 to 2000 ; secondary/primary ratio, 0.1 to 0.8 ; number of lines, 1 to 50 ; and number of samples, 1 to 100 . Analytical results were plotted in 2 dimensions, on which all discriminated fluorescence events are shown in terms of $x$ and $y$ coordinates on a schematic diagram of the membrane. One membrane was scanned in $3 \mathrm{~min}$, including the discrimination step. The validation step using epifluorescence microscopy was then performed, using a $\mathrm{BH} 2$ epifluorescence microscope (Olympus) equipped with an FITC filter block and motorized stage driven by the ScanRDI ${ }^{\mathrm{TM}}$ system.

\section{Bacterial strain and culture conditions}

Specificity tests for FISH and the culture on TCBS were performed on 53 Vibrio and 63 non-Vibrio strains provided from reference and environmental culture collections (Tables S1 and S2). Vibrio strains were grown on marine agar at $30^{\circ} \mathrm{C}$ for $24 \mathrm{~h}$, while non-Vibrio strains were grown at $22^{\circ} \mathrm{C}, 30^{\circ} \mathrm{C}$, or $37^{\circ} \mathrm{C}$ depending on their optimum growth temperature, for $24 \mathrm{~h}$ to $4 \mathrm{~d}$ on marine agar (Difco) for marine strains or nutrient agar (Difco) for the others.

\section{In vitro probe specificity from cultured bacterial strains}

The specificity test, including probe inclusivity and exclusivity tests, was performed with freshly cultured cells. Cell suspensions were prepared from fresh colonies in an appropriate diluent (phosphate saline buffer PBS or artificial seawater, depending on the origin of the strain). Tests were performed using cells in the late stationary growth phase, and $100 \mu \mathrm{L}$ of the cell suspension (diluted severalfold) was filtered onto the CB04 membrane. Hybridization was performed directly on the membrane as described above. Following the washing step, the membrane was air dried and mounted with antibleaching medium (Citifluor AF1; Citifluor, Houdon, United Kingdom) for observations by epifluorescence microscopy using a WIBA filter block for FITC detection (Olympus model AX70, Hamburg, Germany).

\section{Study area and sample collection}

Samples were collected weekly between July 2008 and March 2009 at two coastal stations of the northwestern Mediterranean Sea (Fig. 1). SOLA was a sampling site (maximum depth, $26 \mathrm{~m}$ ) located $\sim 500 \mathrm{~m}$ offshore of Banyuls sur-Mer, France $\left(42^{\circ} 29^{\prime} \mathrm{N}\right.$, $03^{\circ} 08^{\prime} \mathrm{E}$ ) and $\mathrm{FB}$ was a littoral site (maximum depth, $\sim 1 \mathrm{~m}$ ) station located $\sim 10 \mathrm{~m}$ offshore of a beach in Collioure, France. Surface water for each sample was collected using a Niskin bottle. Samples were treated within $4 \mathrm{~h}$ of collection.

Table 1. 16S rRNA-targeted oligonucleotide probes used in this study.

\begin{tabular}{llccc}
\hline Probe & Sequence $\left(5^{\prime}-3^{\prime}\right)$ & $\begin{array}{c}\text { 16S rRNA gene } \\
\text { E. coli position }\end{array}$ & GC\% & Tm $\left({ }^{\circ} \mathrm{C}\right)$ \\
\hline GV & AGGCCACAACCTCCAAGTAG & 822 & 55 & 60.5 \\
VIB572a & ACCACCTGCATGCGCTTT & 571 & 56 & 56.3 \\
Vib749 & TCGCATCTGAGTGTCAGT & 748 & 50 & 53.8 \\
\hline
\end{tabular}




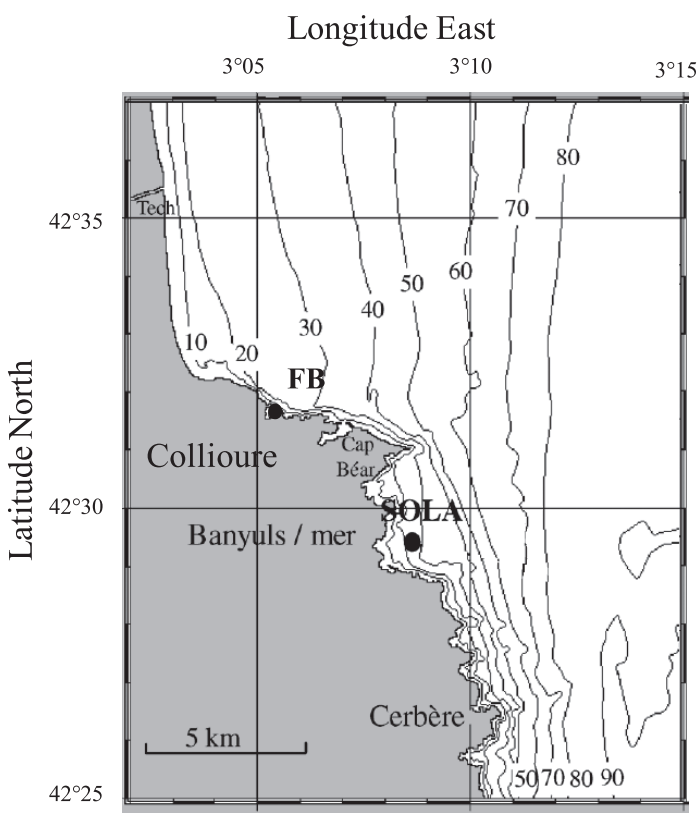

Fig. 1. Location of sampling sites within the northwestern Mediterranean Sea coastal area (SOLA and FB stations).

\section{Seawater sample treatment}

Prior to DVC-FISH-SPC and CFU enumerations, a specific treatment was applied to disperse and disrupt aggregates in seawater samples using an optimized mechanical treatment. Water samples were homogenized as follows: $25 \mathrm{~g}$ of glass beads $(2-3 \mathrm{~mm}$ diameter, Dominique Dutscher, Brumath, France) were added to $60 \mathrm{~mL}$ of water sample. This sample was then mixed using a vortex for $1 \mathrm{~min}$. The homogenized water sample was then used for the DVC assay and CFU enumerations as described below. This treatment increased the measured counts by 5.4- and 1.7-fold over those without the treatment, and decreased the coefficient of variation of the method from $32 \%$ to $24 \%$ and from $29.4 \%$ to $24.7 \%$ for the DVC-FISH-SPC and plate count methods, respectively (data not shown).

\section{Culturable Vibrio counts}

Culturable vibrios were enumerated after the membrane filtration of seawater samples and cultivation on TCBS medium (Biokar Diagnostics, Beauvais, France). Seawater samples (0.1 to $50 \mathrm{~mL}$ ) were filtered in triplicate onto $47-\mathrm{mm}$ nitrocellulose filters with a pore size of $0.45 \mu \mathrm{m}$ (Millipore). Plate incubations were performed at $30^{\circ} \mathrm{C}$ for $24 \mathrm{~h}$ as described previously (48). The temperature for cultivation was the same as the temperature used for the DVC treatment. Colonies (green and yellow) were counted and reported as colony-forming units (CFU) $100 \mathrm{~mL}^{-1}$ water.

\section{Environmental variables}

Surface Seawater Temperature (SST) and salinity were obtained using Seabird SBE19 CTD. Chlorophyll $a(\mathrm{Chl}-a)$ and pheopigment (PHEO) concentrations were measured fluorometrically using a Turner-Designs10-AU fluorometer (29). Samples (2 L) for particulate organic carbon (POC) and nitrogen $(\mathrm{PON})$ were filtered onto combusted Whatman $\mathrm{GF} / \mathrm{F}$ filters $\left(450^{\circ} \mathrm{C}\right.$ for $\left.5 \mathrm{~h}\right)$. Filters were dried $\left(50^{\circ} \mathrm{C}\right.$ for $\left.12 \mathrm{~h}\right)$ and stored in a desiccator until analyzed. POC and PON measurements were performed on a 2400 Perkin Elmer CHN analyzer. The environmental parameters measured at the SOLA site have been provided by the Service d'Observation en Milieu Littoral (SOMLIT) database (http://somlit-db.epoc.u-bordeaux1.fr) and buoy-BOB SOLA (http://smmoob.obs-banyuls.fr/fr/donnees_huate frequence/donnees_de_la_bouees_smm_1_au_point_sola.html).

\section{Statistical analysis}

In the specificity test from cultured strains, the normal distribution of data was tested using the Shapiro-Wilk test and statistical comparisons between different cell counts were made using the pairwise Wilcoxon test.

The relationships among Vibrio counts and all measured environmental variables were investigated using Distance-based linear modeling (DistLM) and a Distance-based redundancy analysis (dbRDA). DistLM allows variations in data distribution to be grouped according to a multiple regression model based on predictor variables. The "forward" procedure and AIC (Akaike's Information Criterion) option were used in the present study. All multivariate analyses were performed using PRIMER 7 and its add-on package PERMANOVA $+(2-5,14)$.

\section{Results}

\section{Probe inclusivity and exclusivity}

The specificity of probes was first analyzed in silico using the ProbeCheck webserver and databases from RDPII, SILVA, and Greengenes. A total of 3,509 sequences belonging to members of Vibrionaceae and including sequences from 103 different species of the genera Vibrio and Alivibrio (ex-Vibrio reclassified) (49) showed a perfect match with at least one of the three probes (Table 2). The GV probe showed a lower specificity by matching perfectly with several members of the genus Photobacterium and one of Grimontia hollisae. All the sequences of Vibrio and Alivibrio (defined as vibrios in our study) showed a perfect match with at least two probes (except $V$. olivaceus).

The specificity of probes was then evaluated against a large panel of cultured bacterial strains previously isolated from marine environmental samples or provided by collections (Tables S1 and S2). All environmental bacterial strains were identified by sequencing of the phylogenetic markers, $16 \mathrm{~S}$ rRNA and $g y r B$ genes. Strains were selected because of their close phylogenetic relationship (Photobacterium) or biotope co-occurrence with Vibrio (i.e., Actinobacteria, members of the CFB group, $\alpha$-Proteobacteria and other members of the $\delta$-Proteobacteria group). All strains were initially isolated from the same culture media and environmental samples.

All vibrios $(100 \%, n=53)$ yielded a strong positive fluorescent signal with the probe set (Fig. S1), and a fluorescent signal was not detected with non-vibrios $(n=63)$. No signal was detected with Photobacterium altlantica type MOLA150, $P$. piscicida type MOLA638, or P. eurosenbergii type PIIA5. These strains only matched the GV probe, which lead to a low fluorescent signal not detectable by epifluorescence microscopy.

\section{TCBS inclusivity and exclusivity}

All vibrio strains $(100 \%, n=53)$ showed growth on TCBS after a 24 -h incubation at $30^{\circ} \mathrm{C}$, as well as some non-vibrios under the same conditions (Tables S1 and S2). These non-vibrios included 3 strains of Actinobacteria belonging to the Microbacteriaceae and Micrococcaceae families, a strain of Staphylococcus aureus, and several strains of $\delta$-Proteobacteria belonging to different phylogenetic families such as Alteromonadaceae, Shewanellaceae, Chromatiaceae, Pseudomonadaceae, and Enterobacteriaceae. Photobacterium 
Table 2. Percentage of sequences available from the ProbeBase database showing a perfect match with oligonucleotide probes. Analyses performed using the Match function of the ProbeBase online resource.

\begin{tabular}{|c|c|c|c|c|c|c|c|}
\hline Affiliation full name ${ }^{a}$ & $\begin{array}{l}\text { Number of } \\
\text { accession } \\
\text { sequences }^{\mathrm{b}}\end{array}$ & $\begin{array}{l}\text { Perfect match } \\
\text { with at least } \\
2 \text { probes }\end{array}$ & $\begin{array}{l}\text { Perfect match } \\
\text { with only } \\
1 \text { probe }\end{array}$ & Affiliation full name ${ }^{a}$ & $\begin{array}{l}\text { Number of } \\
\text { accession } \\
\text { sequences }^{\mathrm{b}}\end{array}$ & $\begin{array}{l}\text { Perfect match } \\
\text { with at least } \\
2 \text { probes }\end{array}$ & $\begin{array}{l}\text { Perfect match } \\
\text { with only } \\
1 \text { probe }\end{array}$ \\
\hline Alivibrio finisterrensis & 4 & 100 & 0 & V. kanaloae & 9 & 100 & 0 \\
\hline A. fischeri* & 55 & 98.2 & 1.8 & $V$. lentus & 13 & 100 & 0 \\
\hline A. $\log e i^{*}$ & 31 & 100 & 0 & $V$. litoralis & 3 & 100 & 0 \\
\hline A. salmonicida* & 12 & 91.7 & 8.3 & V. mangrovi & 1 & 100 & 0 \\
\hline A. sifiae & 2 & 100 & 0 & V. maritimus & 1 & 100 & 0 \\
\hline Aliivibrio sp. & 8 & 100 & 0 & V. mediterranei & 11 & 100 & 0 \\
\hline A. thorii & 1 & 100 & 0 & V. metschnikovii & 13 & 100 & 0 \\
\hline A. wodanis* & 10 & 100 & 0 & V. midae & 1 & 100 & 0 \\
\hline Grimontia hollisae & 2 & 0 & 100 & V. mimicus & 7 & 100 & 0 \\
\hline Photobacterium sp. & 55 & 29.1 & 70.9 & V. mytili & 2 & 100 & 0 \\
\hline Vibrio aerogenes & 2 & 100 & 0 & $V$. natriegens & 35 & 100 & 0 \\
\hline V. aestuarianus & 18 & 100 & 0 & V. navarrensis & 1 & 100 & 0 \\
\hline V. agarivorans & 2 & 100 & 0 & V. neonatus & 6 & 100 & 0 \\
\hline V. albensis & 8 & 100 & 0 & $V$. neptunius & 7 & 100 & 0 \\
\hline V. alginolyticus & 95 & 94.7 & 5.3 & $V$. nereis & 4 & 100 & 0 \\
\hline$V$. algoinfesta & 2 & 100 & 0 & V. nigripulchritudo & 5 & 100 & 0 \\
\hline V. anguillarum & 57 & 98.2 & 1.8 & V. olivaceus & 2 & 0 & 100 \\
\hline V. areninigrae & 1 & 100 & 0 & V. ordalii & 35 & 100 & 0 \\
\hline V. artabrorum & 8 & 100 & 0 & $V$. orientalis & 10 & 100 & 0 \\
\hline$V$. atlanticus & 5 & 100 & 0 & $V$. owensii & 21 & 100 & 0 \\
\hline V. atypicus & 1 & 100 & 0 & V. pacinii & 2 & 100 & 0 \\
\hline V. azureus & 22 & 100 & 0 & V. parahaemolyticus & 148 & 97.8 & 2.0 \\
\hline V. brasiliensis & 7 & 100 & 0 & V. pectenicida & 2 & 100 & 0 \\
\hline V. breoganii & 8 & 100 & 0 & $V$. pelagius & 3 & 100 & 0 \\
\hline V. campbellii & 51 & 100 & 0 & V.penaeicida & 8 & 100 & 0 \\
\hline V. caribbenthicus & 1 & 100 & 0 & V.pomeroyi & 7 & 85.7 & 14.3 \\
\hline V. casei & 2 & 100 & 0 & V. pommerensis & 1 & 100 & 0 \\
\hline V. celticus & 4 & 100 & 0 & V.ponticus & 6 & 100 & 0 \\
\hline V. chagasii & 6 & 100 & 0 & $V$. porteresiae & 4 & 100 & 0 \\
\hline V. cholerae & 176 & 99.4 & 0.6 & V. proteolyticus & 11 & 90.9 & 9.1 \\
\hline V. cincinnatiensis & 1 & 100 & 0 & V. qinhuangdaora & 1 & 100 & 0 \\
\hline$V$. comitans & 13 & 100 & 0 & V.rarus & 2 & 100 & 0 \\
\hline V. communis & 28 & 100 & 0 & V. rhizosphaerae & 2 & 100 & 0 \\
\hline V. coralliilyticus & 15 & 80 & 20 & V. rotiferianus & 28 & 100 & 0 \\
\hline V. crassostreae & 7 & 100 & 0 & V. ruber & 3 & 66.7 & 33.3 \\
\hline V.cyclitrophicus & 20 & 100 & 0 & V. rumoiensis & 8 & 100 & 0 \\
\hline V. diabolicus & 3 & 100 & 0 & $V$. sagamiensis & 2 & 100 & 0 \\
\hline V. diazotrophicus & 7 & 100 & 0 & V. scophthalmi & 4 & 100 & 0 \\
\hline$V$. equitatus & 1 & 100 & 0 & V. shilonii & 13 & 100 & 0 \\
\hline V. ezurae & 6 & 100 & 0 & V. sinaloensis & 10 & 100 & 0 \\
\hline V. fischeri & 4 & 75 & 25 & Vibrio sp. & 1723 & 98.8 & 1.2 \\
\hline V. fluvialis & 8 & 100 & 0 & V. splendidus & 68 & 100 & 0 \\
\hline V. fortis & 16 & 100 & 0 & $V$. superstes & 6 & 100 & 0 \\
\hline V. furnissii & 9 & 100 & 0 & V. tapetis & 15 & 100 & 0 \\
\hline V. gallaecicus & 6 & 100 & 0 & V. tasmaniensis & 7 & 100 & 0 \\
\hline V. gallicus & 6 & 100 & 0 & V. tubiashii & 6 & 100 & 0 \\
\hline V. gazogenes & 2 & 100 & 0 & V. variabilis & 1 & 100 & 0 \\
\hline$V$. gigantis & 32 & 100 & 0 & V. vulnificus & 48 & 100 & 0 \\
\hline$V$. halioticoli & 20 & 100 & 0 & V. xuii & 1 & 100 & 0 \\
\hline V. harveyi & 183 & 99.5 & 0.5 & & & & \\
\hline V. hepatarius & 6 & 100 & 0 & & & & \\
\hline V. hippocampi & 1 & 100 & 0 & & & & \\
\hline V. hispanicus & 4 & 100 & 0 & & & & \\
\hline V. ichthyoenteri & 13 & 100 & 0 & & & & \\
\hline V. indicus & 1 & 100 & 0 & & & & \\
\hline V. inusitatus & 4 & 100 & 0 & & & & \\
\hline
\end{tabular}

${ }^{a}$ Ex-members of the genus Vibrio reclassified as Aliivibrio (49)

$\mathrm{b}$ Total number of accession sequences per species available in databases from RDP-II, SILVA, and Greengenes and showing perfect matches with at least one of the three probes (GV, Vib572a, and Vib749)

strains $(P$. altlantica type MOLA150, $P$. piscicida type MOLA638, and $P$. eurosenbergii type PIIA-5) were also able to grow under these culture conditions. Non-vibrio strains with the ability to grow on TCBS were not detected with the set of multiple probes used for FISH.

\section{Spatial and temporal fluctuations in Vibrio abundance in seawater}

Prior to DVC-FISH-SPC tests, for each environmental water sample, two controls were used to confirm the specificity of the SPC counts of DVC-FISH-treated cells. Any auto-fluorescent cells detected and the fluorescence of hybridized untreated 

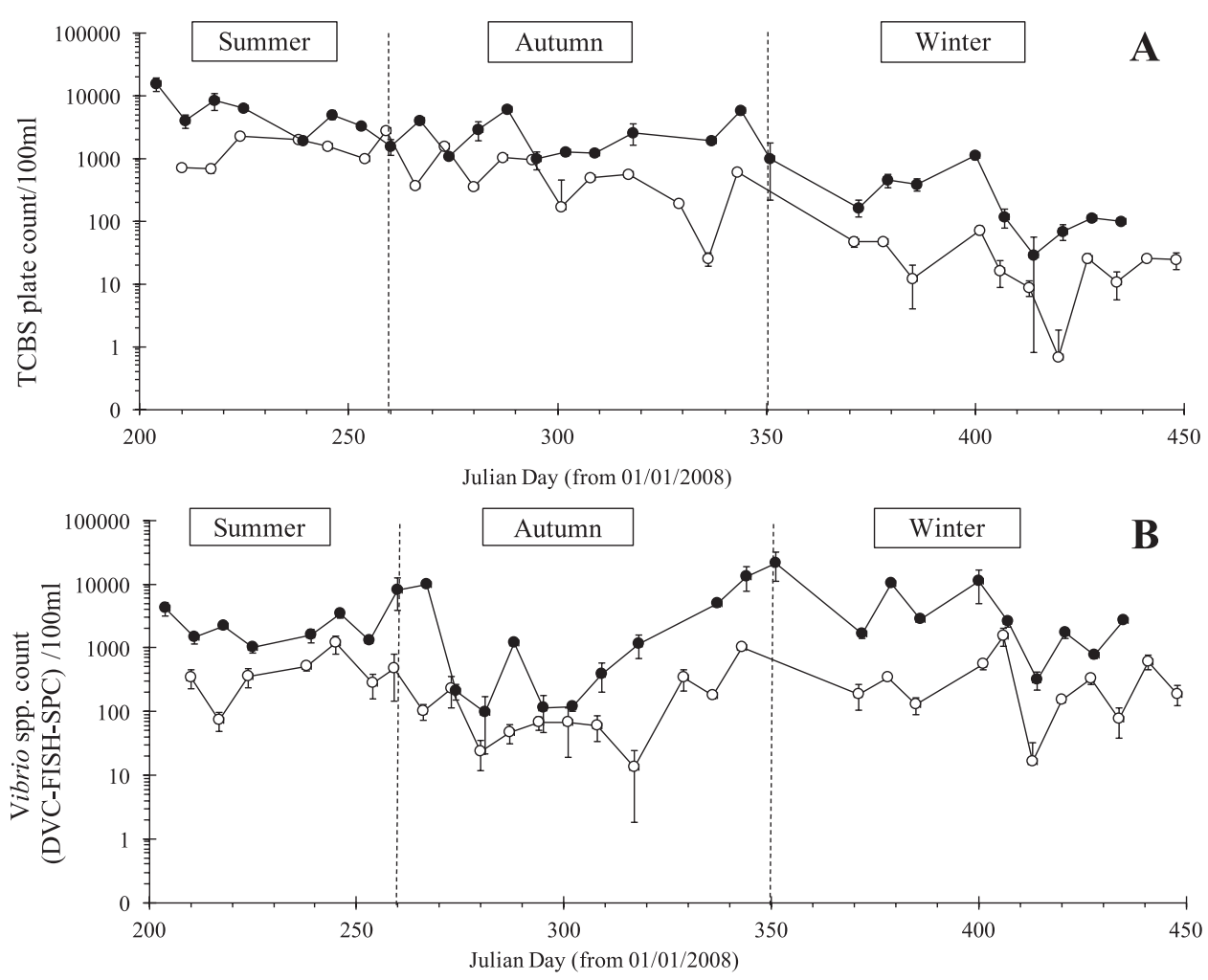

Fig. 2. Weekly variations in TCBS plate counts (A) and Vibrio counts measured by the DVC-FISH-SPC method (B) at FB (black circle) and SOLA (open circle) sampling sites.

DVC cells was below the threshold, leading to no cell detection by SPC. In contrast, DVC-FISH-treated samples showed positive SPC counts indicating that cells were responding positively by increasing their ribosomal content and then showing high intracellular fluorescence after hybridization.

Temporal variations in CFUs (TCBS plate counts) and viable Vibrio cells (DVC-FISH-SPC) at both sampling sites are shown in Fig. 2. In the plate count method, the limit of detection was assessed according to general guidance on the enumeration of microorganisms by culture-ISO 8199 (23) and was $6.0 \mathrm{CFU} 100 \mathrm{~mL}^{-1}$. CFU ranged from below the detection limit $(0.7 \mathrm{CFU})$ to $2.7 \times 10^{3} \mathrm{CFU} 100 \mathrm{~mL}^{-1}$ at the SOLA station and from $2.8 \times 10^{1}$ to $1.5 \times 10^{4} \mathrm{CFU} 100 \mathrm{~mL}^{-1}$ at the FB station. Throughout the study, the abundances of CFU showed the same temporal pattern for both stations with values decreasing progressively between July 2008 (Julian day 204) and March 2009 (Julian day 448). Vibrio abundances measured by the DVC-FISH-SPC assay ranged between $1.3 \times 10^{1}$ and $1.5 \times 10^{3}$ per $100 \mathrm{~mL}$ at the SOLA station and between $9.7 \times 10^{1}$ and $2.1 \times 10^{4}$ per $100 \mathrm{~mL}$ at the FB station. The FB station showed a significantly higher number of viable cells and CFU concentrations than the SOLA station (pairwise Wilcoxon test, $P<0.0001$ ). The annual average concentrations during the period studied were 12- and 4.6-fold higher at FB than at SOLA for DVC-FISH-SPC and plate counts, respectively.

The DVC-FISH-SPC/CFU ratio was calculated for each sample and values ranged between 0.05 (Oct-10) and 230 (Feb-23) and between 0.03 (Oct-07) and 25.2 (Feb-24) at the SOLA and FB stations, respectively. The ratio showed a distinct temporal pattern, in which the lowest values $(<1)$ were globally observed during the summer and autumn seasons (period between July and November), and higher values (up to 230) were observed exclusively during the winter season (period between the end of November and end of the study in March) (Fig. 3).

\section{Spatial and temporal fuctuations in environmental variables}

Both sites showed similar physicochemical characteristics. Temporal variations in environmental parameters in both sampling sites are reported in the supplementary material (Fig. S2) and the annual average values and ranges of variations are summarized in Table 3. Surface water temperature and salinity showed similar patterns at both sampling sites with seasonal variations typical of the Mediterranean climate zone. POC concentrations were highly variable during the investigated period and varied between 3.21 and $34.27 \mu \mathrm{mol} \mathrm{C} \mathrm{L}-1$ (average 8.96) at SOLA and between 4.26 and $30.91 \mu \mathrm{mol} \mathrm{C} \mathrm{L}-1$ (average 11.70) at FB. PON concentrations showed weekly variations with values ranging between 0.47 and $2.64 \mu \mathrm{mol} \mathrm{N} \mathrm{L} \mathrm{N}^{-1}$ (average 1.02) at SOLA and between 0.51 and $3.36 \mu \mathrm{mol} \mathrm{N} \mathrm{L}^{-1}$ (average 1.34) at FB, with the highest values being measured during summer time.

Overall, variable and higher concentrations of Chl- $a$ were found at the FB station (ranging between 0.17 and $1.41 \mu \mathrm{g} \mathrm{L}^{-1}$ ), while lower Chl- $a$ concentrations were measured at the SOLA station; the latter were similar to those measured by Obernosterer et al. (36) in 2003 and 2004 at the same sampling station (ranging between 0.11 and $1.61 \mu \mathrm{g} \mathrm{L} \mathrm{L}^{-1}$ ). Despite high weekly measurement variations, a seasonal dynamic of Chl- $a$ was clearly observed, and two phytoplanktonic blooms were detectable at SOLA in November and February. Nevertheless, 

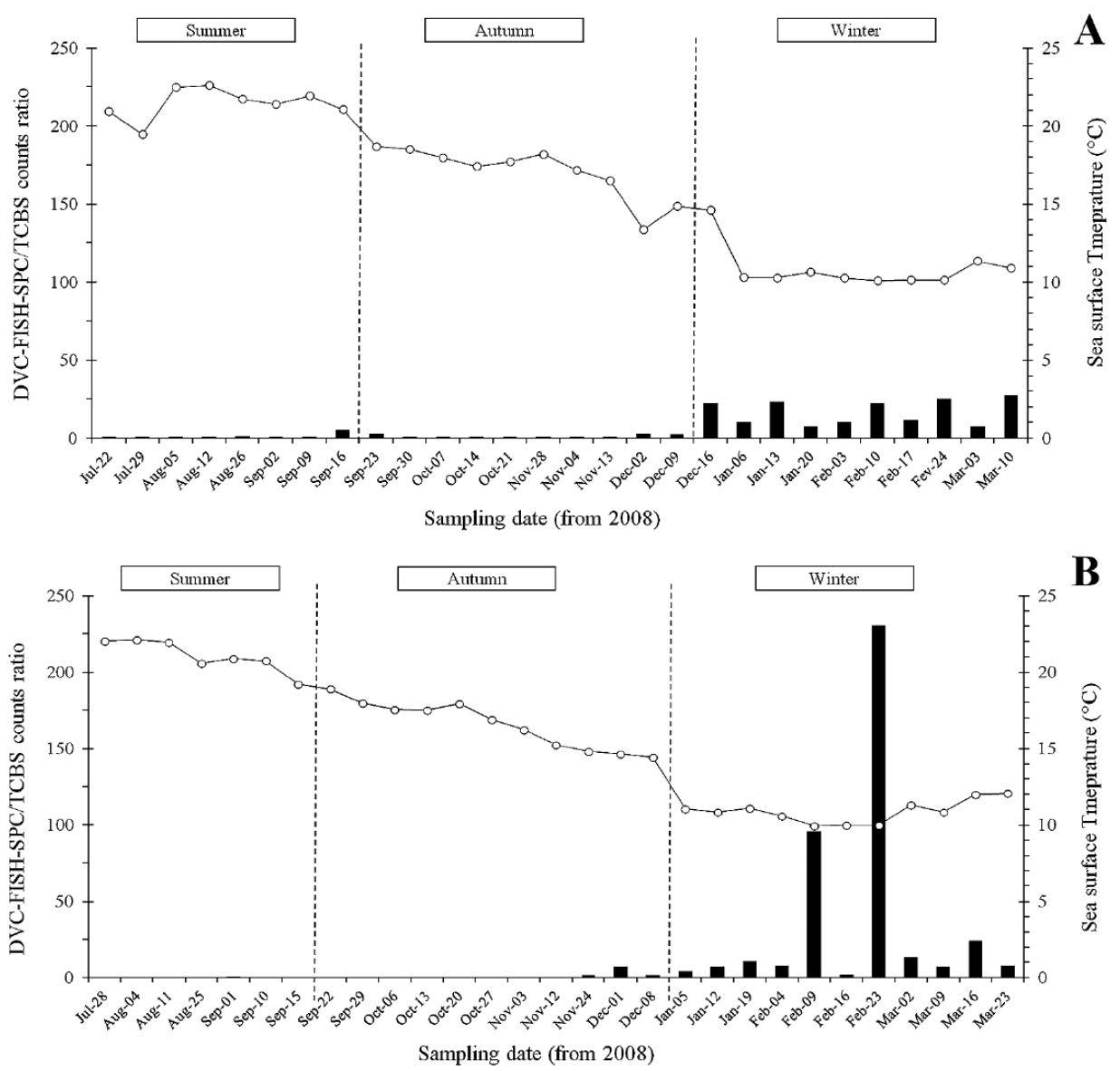

Fig. 3. Weekly variations in the ratio of DVC-FISH-SPC/TCBS plate counts (black bar) and sea surface temperature (open circle) at FB (A) and SOLA (B) sampling sites.

Table 3. Annual average values and ranges of environmental variables.

\begin{tabular}{|c|c|c|c|c|}
\hline & \multicolumn{2}{|c|}{ SOLA site } & \multicolumn{2}{|c|}{ FB site } \\
\hline & Mean & Range & Mean & Range \\
\hline Temperature $\left({ }^{\circ} \mathrm{C}\right)$ & 15.5 & $9.9-22.1$ & 16.0 & $10.1-22.6$ \\
\hline Salinity (PSU) & 37.66 & $36.38-38.14$ & 37.43 & $34.93-38.17$ \\
\hline Chl- $a\left(\mu \mathrm{g} \mathrm{L}^{-1}\right)$ & 0.53 & $0.11-1.61$ & 0.67 & $0.17-1.41$ \\
\hline PHEO $\left(\mu \mathrm{g} \mathrm{L}^{-1}\right)$ & 0.48 & $0.06-1.17$ & 0.76 & $0.17-1.29$ \\
\hline $\mathrm{PON}\left(\mu \mathrm{mol} \mathrm{N} \mathrm{L}{ }^{-1}\right)$ & 1.02 & $0.47-2.64$ & 1.34 & $0.51-3.36$ \\
\hline $\mathrm{POC}(\mu \mathrm{mol} \mathrm{C} \mathrm{L}-1)$ & 8.96 & $3.21-34.27$ & 11.70 & $4.26-30.91$ \\
\hline Total Suspended Matter & & & & \\
\hline$(\mathrm{TSM})\left(\mu \mathrm{g} \mathrm{L}^{-1}\right)$ & 1.84 & $0.29-8.5$ & - & \\
\hline Turbidity (NTU) & - & & 3.43 & $0.73-19.69$ \\
\hline Dissolved oxygen $\left(\mathrm{ml} \mathrm{L}^{-1}\right)$ & 5.88 & $4.99-6.48$ & - & \\
\hline $\mathrm{pH}$ & 8.17 & $7.93-8.32$ & - & \\
\hline Ammonia $\left(\mu \mathrm{mol} \mathrm{L}{ }^{-1}\right)$ & 0.22 & $0.05-1.19$ & - & \\
\hline Nitrates $\left(\mu \mathrm{mol} \mathrm{L} \mathrm{L}^{-1}\right)$ & 1.12 & $0.01-5.73$ & - & \\
\hline Nitrites $\left(\mu \mathrm{mol} \mathrm{L} \mathrm{L}^{-1}\right)$ & 0.17 & $0.03-0.80$ & - & \\
\hline Phosphates $\left(\mu \mathrm{mol} \mathrm{L}{ }^{-1}\right)$ & 0.03 & $0.02-0.08$ & - & \\
\hline Silicates $(\mu \mathrm{mol} \mathrm{L}-1)$ & 1.79 & $0.07-6.27$ & - & \\
\hline
\end{tabular}

the maximum Chl- $a$ measured during those blooms remained low $\left(1.1\right.$ and $\left.1.6 \mu \mathrm{g} \mathrm{L}^{-1}\right)$. PHEO concentrations were higher at FB (range, 0.17-1.41 $\mu \mathrm{g} \mathrm{L}^{-1}$ ) than at SOLA (range, $0.06-1.17 \mu \mathrm{g} \mathrm{L}^{-1}$ ) and the pattern of temporal variation was similar to that obtained for Chl- $a$ concentrations.

\section{Relationship between vibrios and environmental variables}

The relationship between Vibrio abundance and environmental variables was investigated by DistLM and the dbRDA analysis. Abundances measured by TCBS plate counts and the DVC-FISH-SPC method were investigated separately for each sampling site. Culturable count variations for both sampling sites of $62 \%$ and $51 \%$, respectively, for FB and SOLA were explained by temperature. The most important factors explaining variations in DVC-FISH-SPC data were PHEO (15\% variation) for the FB station and phosphate concentrations (12\% variation) at the SOLA station (Table 4).

\section{Discussion}

The most studied physiological adaptation for vibrios is the VBNC state. This state is a survival strategy adopted by many Vibrio species when environmental conditions are unsuitable for sustaining normal growth. In this physiological condition, bacteria exhibit detectable metabolic function, but are not culturable by conventional laboratory culture-based methods. The DVC assay offers cell viability measurements after a short incubation with antimicrobial agents, acting as a specific inhibitor of DNA synthesis and cell division, without affecting other cellular metabolic activities. Cell identification may be achieved through the use of taxonomic probes such as fluorescent oligonucleotide probes or antibodies (25).

The DVC was extensively applied in combination with fluorescent antibodies to investigate the VBNC state of $V$. cholera $(10,31,33)$. In the present study, we combined the DVC with a FISH approach employing a one-step multiple- 
Table 4. Non-parametric multivariate analysis of variance (DISTLM) using Bray-Curtis dissimilarities comparing total viable vibrios and TCBS counts (square root transformed) and physicochemical parameters. Proportion of variance in Vibrio counts explained by environmental variables in forward sequential tests following AIC selection criterion with a $p$ value $<0.05$. Prop. is the proportion of variance explained by each single variable, res.df $=$ residual degrees of freedom.

\begin{tabular}{cccrrrrr}
\hline $\begin{array}{c}\text { Sampling station/ } \\
\text { variable }\end{array}$ & Variable $^{\mathrm{a}}$ & AIC & SS (trace) & Pseudo-F & $p$ value & Prop. \% & res.df \\
\hline FB/DVC & PHEO & 220.26 & 8810.7 & 4.811 & 0.004 & $15 \%$ & 27 \\
FB/CFU & SST & 188.35 & 17233.0 & 28.279 & 0.001 & $51 \%$ & 27 \\
SOLA/DVC & Phosphates & 187.89 & 2287.7 & 3.814 & 0.043 & $12 \%$ & 27 \\
SOLA/CFU & SST & 188.09 & 26110.0 & 43.240 & 0.001 & $62 \%$ & 27 \\
\hline
\end{tabular}

a PHEO, concentration of pheopigments; SST, Sea Surface temperature.

probe technique to cover the large diversity of Vibrio species. The genus Vibrio currently consists of more than 150 identified species. An in silico analysis showed a perfect match with at least two probes for a 103 -set of sequences affiliated to different Vibrio and Aliivibrio species, except for $V$. olivaceus (that only matches the GV probe). The tests performed with cultured strains confirmed the high specificity of the FISH protocol for members of the Vibrio and Aliivibrio genera. The approach used in this study allows the simultaneous recognition of Vibrio species with at least two labeled oligonucleotides enhancing the intracellular fluorescent signal of hybridized cells and increasing the signal/noise ratio.

Classical tools used in microbial ecology such as epifluorescent microscopy or flow cytometry are not adapted to detect low abundances of target bacteria among a large number of non-targeted cells in water samples $(7,8,27)$. SPC offers excellent detection limits that allow for low density enumeration when combined with DVC-FISH (as few as 1 target cell $\left.100 \mathrm{~mL}^{-1}\right)(6-8,40)$. The range of bacterial abundance measured by DVC-FISH-SPC in the present study was between 13 and $2.1 \times 10^{4}$ per $100 \mathrm{~mL}$. This result confirmed the excellent sensitivity of the method. Moreover, we observed the high temporal variability of Vibrio abundance at a weekly frequency, highlighting their short-term dynamics.

Many studies have investigated the environmental factors potentially driving the dynamics of Vibrio species, particularly in coastal areas. Nevertheless, these investigations targeted culturable populations by plate counts or total cells by qPCR methods; the dynamics of viable vibrios including VBNC cells were not investigated $(13,21,51)$. Our results confirmed that SST is a significant driver of culturable Vibrio in temperate areas (45). As expected, both sites revealed the same temporal pattern for bacterial abundances. CFU concentrations were 4- to 13-fold higher during the warmer months (summer season) for SOLA and FB, respectively, and showed gradually decreasing abundances in autumn and winter. A similar seasonal distribution of culturable vibrios was reported in the Ligurian and Adriatic Seas $(13,52)$. Total viable counts (DVC-FISH-SPC) showed a different seasonal pattern from the plate counts with slight increases, up to 10-100-fold, at the end of autumn, and the highest concentrations during winter.

During the summer period, the DVC-FISH-SPC/CFU ratio showed unexpectedly low values, suggesting the growth of non-Vibrio on TCBS, as already reported $(20,34)$. During the colder period $\left(\mathrm{SST}<15^{\circ} \mathrm{C}\right)$, this ratio was systematically higher than 1 (ranged between 1.7 to a maximum of 230), highlighting that an important proportion of vibrios enter the VBNC state.

Although we demonstrated the efficiency of the DVC treatment, not all Vibrio cells may be responding equally. Consequently, our DVC method may have some limitations related to the resuscitation of all Vibrio members. However, our results confirmed that a decrease in SST is the factor contributing to the shift in the culturable population toward a VBNC state, as reported for many Vibrio species $(28,37,50$, 54). The DISTLM analysis confirmed previous results that temperature is the key factor explaining the dynamics of culturable vibrios; however, it also revealed that temperature was not an explanatory variable for the dynamic of total viable vibrios.

Phosphate concentrations were an explanatory variable of the viable cell distribution at the SOLA station and in the absence of bulk measurements of dissolved oxygen, nitrogen, silicates, and phosphate concentrations at FB, PHEO concentrations mainly explained the variations observed at the FB station. PHEO are quantitatively important in marine sediments and include many degradation products of living chlorophylls due to the senescence of phytoplankton and grazing pressure from herbivorous organisms $(12,13)$. During the present study, each increase in PHEO concentrations at the FB station may be related to high turbidity or a decline in phytoplanktonic blooms (Fig. S2). Since the FB station is a shallow littoral station with a maximum depth of $\sim 1 \mathrm{~m}$, the relationship between turbidity and PHEO in earlier autumn and winter may be explained by marine sediment resuspension events. At the SOLA station, phosphate concentrations in seawater, explaining only $12 \%$ of the viable cell distribution throughout the year, may act as an indirect factor in Vibrio community dynamics. High phosphate concentrations co-occurring with high concentrations of nitrates, silicates, and a decrease in salinity may be related to continental freshwater inputs. Consequently, the relationship between phosphate concentrations and the viable population of Vibrio during the winter season may be explained by a direct impact on bacterial activity or an indirect impact by promoting phytoplankton growth, for example, pico- and nanophytoplanktons (M. Pujo-Pay, personal communication).

The differences between sites and limited explanation by environmental factors suggest complex ecological scenarios for the maintenance of viable vibrios in coastal areas; for example, species-specific adaptations shaped by multiple sets of environmental factors at a local and short-term scale. Our results emphasize the importance of the selection of a meth- 
odological approach to investigate the dynamics of vibrios. We highlighted the need to deploy environmental studies at high temporal frequencies in order to understand the factors supporting the viability of vibrios in coastal areas.

\section{Acknowledgements}

We are thankful to the Service d'Observation du Laboratoire ARAGO for the sampling campaigns at SOLA, and for the physicochemical analysis performed on water samples. We also thank Eric Maria and Jocelyne Caparros for the nutrient analysis and Dr. Mireille Pujo-Pay for her support in the interpretation of temporal variations in nutrients. We are thankful to Nyree West for the careful reading of the final manuscript.

\section{References}

1. Alam, M., A. Sadique, Nur-A-Hasan, et al. 2006. Effect of transport at ambient temperature on detection and isolation of Vibrio cholerae from environmental samples. Appl. Environ. Microbiol. 72:21852190.

2. Anderson, M.J. 2001a. A new method for non-parametric multivariate analysis of variance. Austral. Ecol. 26:32-46.

3. Anderson, M.J. 2001b. Permutation tests for univariate or multivariate analysis of variance and regression. Can. Fish Aquatic Sci. 58:626639.

4. Anderson, M.J. 2005. PERMANOVA: A fortran computer program for permutational multivariate analysis of variance. Auckland: Department of Statistics, University of Auckland. New Zealand.

5. Anderson, M.J., R.N. Gorley, and K.R. Clarke. 2008. PERMANOVA+ for Primer: guide to software and statistical methods PRIMER-E Ltd., Plymouth.

6. Baudart, J., J. Coallier, P. Laurent, and M. Prévost. 2002. Rapid and sensitive enumeration of viable diluted cells of members of the family Enterobacteriaceae in freshwater and drinking water. Appl. Environ. Microbiol. 68:5057-5063.

7. Baudart, J., and P. Lebaron. 2010. Rapid detection of Escherichia coli in waters using fluorescent in situ hybridization, direct viable counting and solid phase cytometry. J. Appl. Microbiol. 109:1253-1264.

8. Baudart, J., A. Robyns, S. Peuchet, J.L. Drocourt, and P. Lebaron. 2011. Sensitive counting of viable Enterobacteriaceae in seawaters and relationship with fecal indicators. J. Microbiol. Methods 84:482485.

9. Berlin, D.L., D.S. Herson, D.T. Hicks, and D.G. Hoover. 1999. Response of pathogenic Vibrio species to high hydrostatic pressure. Appl. Environ. Microbiol. 65:2776-2780.

10. Binsztein, N., M.C. Costagliola, M. Pichel, V. Jurquiza, F.C. Ramírez, R. Akselman, M. Vacchino, A. Huq, and R. Colwell. 2004. Viable but nonculturable Vibrio cholerae $\mathrm{O} 1$ in the aquatic environment of Argentina. Appl. Environ. Microbiol. 70:7481-7486.

11. Blackwell, K.D., and J.D. Oliver. 2008. The ecology of Vibrio vulnificus, Vibrio cholerae, and Vibrio parahaemolyticus in North Carolina estuaries. J. Microbiol. 46:146-153.

12. Bourgeois, S., A.M. Pruski, M.Y. Sun, R. Buscail, F. Lantoine, P. Kerhervé, G. Vétion, B. Rivière, and F. Charles. 2011. Distribution and lability of land-derived organic matter in the surface sediments of the Rhône prodelta and the adjacent shelf (Mediterranean Sea, France): a multi proxy study. Biogeosciences 8:3107-3125.

13. Caburlotto, G., F. Bianchi, M. Gennari, V. Ghidini, G. Socal, F.B. Aubry, M. Bastianini, M. Tafi, and M.M. Lleo. 2012. Integrated evaluation of environmental parameters influencing Vibrio occurrence in the coastal Northern Adriatic Sea (Italy) facing the Venetian lagoon. Microb. Ecol. 63:20-31.

14. Clarke, K.R., and R.M. Warwick. 2001. Change in Marine Communities: An Approach to Statistical Analysis and Interpretation, 2nd edn. PRIMER-E, Plymouth.

15. Colwell, R.R. 2009. Viable but non cultivable bacteria, p. 121-9. In S.S. Epstein (ed.), Uncultivated Microorganisms. Berlin: Springer Verlag.

16. Du, M., J. Chen, X. Zhang, A. Li, and Y. Li. 2007. Characterization and resuscitation of viable but nonculturable Vibrio alginolyticus VIB283. Arch. Microbiol. 188:283-288.
17. Fernández-Delgado, M., M.A. García-Amado, M. Contreras, R.N. Incani, H. Chirinos, H. Rojas, and P. Suárez. 2015. Survival, induction and resuscitation of Vibrio cholerae from the viable but non-culturable state in the Southern Caribbean Sea. Rev. Inst. Med. Trop. Sao Paulo. 57:21-26.

18. Giuliano, L., M. De Domenico, E. De Domenico, M.G. Höfle, and M.M. Yakimov. 1999. Identification of culturable oligotrophic bacteria within naturally occurring bacterioplankton communities of the Ligurian sea by $16 \mathrm{~S}$ rRNA sequencing and probing. Microb. Ecol. 37:77-85.

19. Heidelberg, J.F., K.B. Heidelberg, and R.R. Colwell. 2002. Seasonality of Chesapeake Bay bacterioplankton species. Appl. Environ. Microbiol. 68:5488-5497.

20. Hervio-Heath, D., R.R. Colwell, A. Derrien, A. Robert-Pillot, J.M. Fournier, and M. Pommepuy. 2002. Occurrence of pathogenic vibrios in coastal areas of France. J. Appl. Microbiol. 92:1123-1135.

21. Hsieh, J.L., J.S. Fries, and R.T. Noble. 2008. Dynamics and predictive modeling of Vibrio spp. in the Neuse River Estuary, North Carolina, USA. Environ. Microbiol. 10:57-64.

22. Huggett, M.J., J.E. Williamson, R. de Nys, S. Kjelleberg, and P.D. Steinberg. 2006. Larval settlement of the common Australian sea urchin Heliocidaris erythrogramma in response to bacteria from the surface of coralline algae. Oecologia 149:604-619.

23. ISO $2005-$ Water quality - General guidance on the enumeration of micro-organisms by culture (ISO 8199). International Organization for Standardization, Geneva.

24. Jones, B.W., A. Maruyama, C.C. Ouverney, and M.K. Nishiguchi. 2007. Spatial and temporal distribution of the Vibrionaceae in coastal waters of Hawaii, Australia, and France. Microb. Ecol. 54:314-323.

25. Joux, F., and P. Lebaron. 2000. Use of fluorescent probes to assess physiological functions of bacteria at single-cell level. Microbes Infect. 2:1523-1535.

26. Kogure, K., U. Simidu, and N. Taga. 1979. A tentative direct microscopic method for counting living marine bacteria. Can. J. Microbiol. $25: 415-420$

27. Lemarchand, K., N. Parthuisot, P. Catala, and P. Lebaron. 2001. Comparative assessment of epifluorescent microscopy, flow cytometry and solid-phase cytometry used in the enumeration of specific bacteria in water. Aquat. Microb. Ecol. 25:301-309.

28. Li, L., N. Mendis, H. Trigui, J.D. Oliver, and S.P. Faucher. 2014. The importance of the viable but non-culturable state in human bacterial pathogens. Front. Microbiol. 5:258.

29. Lorenzen, C.L. 1967. Determination of chlorophyll and pheo-pigments: Spectrophotometric equations. Limnol. Oceanogr. 12:343-346.

30. Loy, A., F. Maixner, M. Wagner, and M. Horn. 2007. ProbeBase - an online resource for rRNA-targeted oligonucleotide probes: new features 2007. Nucleic Acids Res. 35:D800-D804.

31. Martinelli Filho, J.E., R.M. Lopes, I.N.G. Rivera, and R.R. Colwell. 2011. Vibrio cholerae O1 detection in estuarine and coastal zooplankton. J. Plankton Res. 33:51-62.

32. Mignon-Godefroy, K., J.G. Guillet, and C. Butor. 1997. Solid phase cytometry for detection of rare events. Cytometry 27:336-344.

33. Mishra, A., N. Taneja, and M. Sharma. 2011. Demonstration of viable but nonculturable Vibrio cholerae $\mathrm{O} 1$ in fresh water environment of India using ciprofloxacin DFA-DVC method. Lett. Appl. Microbiol. 53:124-126.

34. Oberbeckmann, S., A. Wichels, K.H. Wiltshire, and G. Gerdts. 2011. Occurrence of Vibrio parahaemolyticus and Vibrio alginolyticus in the German Bight over a seasonal cycle. Antonie Van Leeuwenhoek. 100:291-307.

35. Oberbeckmann, S., B.M. Fuchs, M. Meiners, A. Wichels, K.H. Wiltshire, and G. Gerdts. 2012. Seasonal dynamics and modeling of a Vibrio community in coastal waters of the North Sea. Microb. Ecol. 63:543-551.

36. Obernosterer, I., R. Lami, M. Larcher, N. Batailler, P. Catala, and P. Lebaron. 2010. Linkage between bacterial carbon processing and the structure of the active bacterial community at a coastal site in the NW Mediterranean Sea. Microb. Ecol. 59:428-435.

37. Oliver, J.D. 2010. Recent findings on the viable but nonculturable state in pathogenic bacteria. FEMS Microbiol. Rev. 34:415-425.

38. Pfeffer, C., and J.D. Oliver. 2003. A comparison of thiosulphatecitrate-bile salts-sucrose (TCBS) agar and thiosulphate-chlorideiodide (TCI) agar for the isolation of Vibrio species from estuarine environments. Lett. Appl. Microbiol. 36:150-151. 
39. Sawabe, T., A. Yoshizawa, Y. Kawanishi, E. Komatsu-Takeda, S. Nakagawa, T. Sawabe, M. Ootubo, M. Satomi, Y. Yano, and K. Yamazaki. 2009. Multi-probe-fluorescence in situ hybridization for the rapid enumeration of viable vibrio parahaemolyticus. Microbes Environ. 24(3):259-264.

40. Schauer, S., R. Sommer, A.H. Farnleitner, and A.K. Kirschner. 2012. Rapid and sensitive quantification of Vibrio cholerae and Vibrio mimicus cells in water samples by use of catalyzed reporter deposition fluorescence in situ hybridization combined with solid-phase cytometry. Appl. Environ. Microbiol. 78:7369-7375.

41. Schauer, S., S. Jakwerth, R. Bliem, et al. 2015. Dynamics of Vibrio cholerae abundance in Austrian saline lakes, assessed with quantitative solid-phase cytometry. Environ. Microbiol. 17:4366-4378.

42. Simidu, U., and K. Tsukamoto. 1980. A method of the selective isolation and enumeration of marine Vibrionaceae. Microb. Ecol. 6:181-184.

43. Stabili, L., M.I. Acquaviva, and R.A. Cavallo. 2005. Mytilus galloprovincialis filter feeding on the bacterial community in a Mediterranean coastal area (Northern Ionian Sea, Italy). Water Res. 39:469-477.

44. Sun, F., J. Chen, L. Zhong, X.H. Zhang, R. Wang, Q. Guo, and Y. Dong. 2008. Characterization and virulence retention of viable but nonculturable Vibrio harveyi. FEMS Microbiol. Ecol. 64:37-44.

45. Takemura, A.F., D.M. Chien, and M.F. Polz. 2014. Associations and dynamics of Vibrionaceae in the environment, from the genus to the population level. Front. Microbiol. 5:38.

46. Tall, A., D. Hervio-Heath, A. Teillon, C. Boisset-Helbert, R. Delesmont, J. Bodilis, and A. Touron-Bodilis. 2013. Diversity of Vibrio spp. isolated at ambient environmental temperature in the Eastern English Channel as determined by $p y r H$ sequencing. J. Appl. Microbiol. 114:1713-1724.

47. Thompson, J.R., M.A. Randa, L.A. Marcelino, A. Tomita-Mitchell, E. Lim, and M.F. Polz. 2004. Diversity and dynamics of a north atlantic coastal Vibrio community. Appl. Environ. Microbiol. 70:4103-4110.
48. Turner, J.W., B. Good, D. Cole, and E.K. Lipp. 2009. Plankton composition and environmental factors contribute to Vibrio seasonality. ISME J. 3:1082-1092.

49. Urbanczyk, H., J.C. Ast, M.J. Higgins, J. Carson, and P.V. Dunlap. 2007. Reclassification of Vibrio fischeri, Vibrio logei, Vibrio salmonicida and Vibrio wodanis as Alivibrio fischeri gen. nov., comb. nov., Alivivibrio logei comb. nov., Aliivibrio salmonicida comb. nov. and Aliivibrio wodanis comb. nov. Int. J. Syst. Evol. Microbiol. 57:28232829.

50. Vattakaven, T., P. Bond, G. Bradley, and C.B. Munn. 2006. Differential effects of temperature and starvation on induction of the viable-but-nonculturable state in the coral pathogens Vibrio shiloi and Vibrio tasmaniensis. Appl. Environ. Microbiol. 72:6508-6513.

51. Vezzulli, L., E. Pezzati, M. Moreno, M. Fabiano, L. Pane, and C. Pruzzo. 2009. Benthic ecology of Vibrio spp. and pathogenic Vibrio species in a coastal Mediterranean environment (La Spezia Gulf, Italy). Microb. Ecol. 58:808-818.

52. Vezzulli, L., C. Pruzzo, A. Huq, and R.R. Colwell. 2010 Environmental reservoirs of Vibrio cholerae and their role in cholera. Environ. Microbiol. Rep. 2:27-33.

53. Vezzulli, L., I. Brettar, E. Pezzati, P.C. Reid, R.R. Colwell, M.G Höfle, and C. Pruzzo. 2012. Long-term effects of ocean warming on the prokaryotic community: evidence from the vibrios. ISME J. $6: 21-30$

54. Vezzulli, L., E. Pezzati, I. Brettar, M. Höfle, and C. Pruzzo. 2015. Effects of Global Warming on Vibrio Ecology. Microbiol. Spectrum 3(3):VE-0004-2014.

55. West, P.A., E. Russek, P.R. Brayton, and R.R. Colwell. 1982 Statistical evaluation of a quality control method for isolation of pathogenic Vibrio species on selected thiosulfate-citrate-bile salts sucrose agars. J. Clin. Microbiol. 16:1110-1116.

56. Zhang, X., K. Li, S. Wu, J. Shuai, and W. Fang. 2015. Peptide nucleic acid fluorescence $i n$-situ hybridization for identification of Vibrio spp. in aquatic products and environments. Int. J. Food. Microbiol. 206:39-44. 